\title{
Evaluation of selected properties of a new root repair cement containing surface pre-reacted glass ionomer fillers.
}

\author{
Ghaeth H. Yassen ${ }^{\mathrm{a}}$, Ruijie Huang ${ }^{\mathrm{a}}$, Afnan Al-Zain ${ }^{\mathrm{a}, \mathrm{b}}$, Takamitsu \\ Yoshida $^{a}$, Richard L. Gregory ${ }^{a}$, Jeffrey A. Platt ${ }^{a}$
}

aDepartment of Biomedical and Applied Sciences, Indiana University School of Dentistry, 1121 W Michigan St, Indianapolis, IN 46202, USA.

${ }^{b}$ Division of Operative Dentistry, Department of Conservative Sciences, faculty of Dentistry, King Abdulaziz University, Jeddah, KSA.

\section{Corresponding author:}

Ghaeth H. Yassen, Department of Biomedical and Applied Sciences, Indiana University School of Dentistry, 1121 W Michigan St, Indianapolis, IN, 46202.

Tel.: +1-317-437-2240

Fax: +1-317-278-7462

E-mail address: gyassen@iupui.edu

\section{Acknowledgments}

This study was funded by Shofu Inc. The funding source had no involvement in data collection, analysis, interpretation, or in the decision to submit the article for publication.

This is the author's manuscript of the article published in final edited form as: Yassen, G. H., Huang, R., Al-Zain, A., Yoshida, T., Gregory, R. L., \& Platt, J. A. (2016). Evaluation of selected properties of a new root repair cement containing surface pre-reacted glass ionomer fillers. Clinical Oral Investigations, 1-10. http://doi.org/10.1007/s00784-016-1715-5 


\begin{abstract}
Objective: This study evaluated selected properties of a prototype root repair cement containing surface pre-reacted glass ionomer fillers (S-PRG) in comparison to mineral trioxide aggregate (MTA) and intermediate restorative material (IRM).

Materials and methods: The antibacterial effect of S-PRG, MTA and IRM cements were tested against Porphyromonas gingivalis and Enterococcus faecalis after one and three-days of aging of the cements. Set cements were immersed in distilled water for 4 hours to 28 days and ion releasing ability was evaluated. Initial and final setting times of all cements were evaluated using Gilmore needles. The push-out bond strength between radicular dentin and all cements was tested at different levels of the roots.

Results: S-PRG and IRM cements but not MTA cement demonstrated significant antibacterial effect against Porphyromonas gingivalis. All types of cements exhibited significant antibacterial effect against Enterococcus faecalis without being able to eliminate the bacterium. S-PRG cement provided continuous release of fluoride, strontium, boron, sodium, aluminum and zinc throughout all tested time points. Both initial and final setting times were significantly shorter for S-PRG and IRM cements in comparison to MTA. The push-out bond strength was significantly lower for S-PRG cement in comparison to MTA and IRM at coronal and middle levels of the roots.
\end{abstract}

Conclusions: S-PRG cement demonstrated significant antibacterial effects against endodontic pathogens, multiple ion releasing ability, relatively short setting time and low bonding strength.

Clinical relevance: $\mathrm{S}-\mathrm{PRG}$ cement can be used as a one-visit root repair material with promising antibacterial properties and ion releasing capacity.

Keywords: IRM, Ion release, MTA, setting time, Push-out bond strength, S-PRG fillers 


\section{Introduction}

Various endodontic repair cements have been used in different procedures such as rootend fillings during endodontic microsurgical techniques, perforation repairs, and artificial apical barriers in necrotic teeth with immature roots. The most widely used root-end filling material is a mineral trioxide aggregate (MTA), which is a calcium-silicate cement. MTA possesses several advantages, such as good sealing ability [1], acceptable mechanical properties [2], biocompatibility [3], and some antibacterial properties [4, 5]. However, the main drawbacks of MTA are its high cost, low radiopacity, difficult manipulation and long setting time $[2,6]$. The 3 4 hour setting time of MTA might increase the risk of wash-out of the freshly applied cement in excessively wet environments [7]. Other dental materials, such as dental amalgam, intermediate restorative material (IRM), and Super EBA have also been used as root-end filling materials. Indeed, the clinical success rate of MTA root-end filling was found to be comparable to IRM $[8$, 9] and Super-EBA [10].

Recently, various dental materials containing surface pre-reacted glass-ionomer fillers (SPRG) were introduced by Shofu Inc. [11]. Multiple S-PRG-based dental materials are commercially available and have been collectively categorized as Giomer (Glass ionomer + polymer) [12]. The S-PRG fillers are prepared by the initiation of an acid-base reaction between fluoroboroaluminosilicate glass and aqueous polyacrylic acid. These bioactive S-PRG particles are thought to promote remineralization [13] and induce antibacterial effects $[14,15]$ through the release of multiple ions such as fluoride, strontium, sodium, boron, aluminum and silicon [16, 17]. The aim of this study was to evaluate selected antibacterial, physiochemical and bonding properties of a prototype S-PRG filler-based root repair cement in comparison to commercially available materials used as root repair cements, namely MTA and IRM. 


\section{Materials and methods}

\section{Root cement materials}

A prototype of S-PRG filler containing root repair cement was provided by Shofu (SPRG root cement, Lot No. 14315, SHOFU, Kyoto, Japan). Furthermore, MTA (ProRoot MTA, Lot No. 201404-01, Dentsply Tulsa, TN, USA) and IRM (Intermediate Restorative Material, Lot No. 130605, Dentsply Caulk, DE, USA) were also used in this study.

\section{Bacterial strains and culture conditions}

Porphyromonas gingivalis (ATCC 33277) and Enterococcus faecalis (ATCC 29212) were selected because they are the most frequent endodontic pathogens present in primary [18, 19] and secondary root canal infections [20,21], respectively. The selected bacteria were individually grown on blood agar plates (CDC; BioMerieux, Durham, NC, USA). Colonies of both bacteria were then suspended separately in brain-heart infusion (BHI) broth supplemented with $5 \mathrm{~g}$ yeast extract/L and 5\% v/v vitamin $\mathrm{K}+$ hemin (BHI-YE; Becton, Dickinson and Company, Franklin Lakes, NJ, USA) to make suspensions of $1 \times 10^{6} \mathrm{CFU} / \mathrm{mL}$ of E. faecalis or P. gingivalis after $24 \mathrm{~h}$ incubation at $37^{\circ} \mathrm{C}$ with $5 \% \mathrm{CO}_{2}$. Gas-generating sachets (Gas-Pak EZ; Becton) were used to create the required anaerobic environment for $P$. gingivalis.

\section{Preparation of cement discs and antibacterial testing}

Each of the three tested cements was mixed according to the manufacturer's instructions and placed into polyvinyl molds with a $4 \mathrm{~mm}$ diameter and $2 \mathrm{~mm}$ height to make cement discs. Then, the discs were incubated for 1 or 3 days at $37^{\circ} \mathrm{C}$ and approximately $100 \%$ relative humidity. After each time point, the discs were removed, immersed in $70 \%$ ethanol for 10 seconds as described in previous studies $[22,23]$ and flamed dry prior to use. Discs were individually immersed in glass tubes containing $5 \mathrm{~mL}$ of $E$. faecalis or $P$. gingivalis bacterial 
suspension and incubated for 48 hours. Glass tubes containing the same volume of bacterial suspension without cement discs were also incubated as controls. Furthermore, pilot studies were conducted to confirm the absence of any turbidity after short term immersion of various cements into bacteria-free culture media. After the 48 hours of incubation, glass tubes with or without cement discs were vortexed for 10 seconds. Then, $200 \mu 1$ of bacterial suspension from each tube was transferred into a microtiter plate (Fisher Scientific Inc., Fair Lawn, New Jersey, USA) and the optical density absorbance was read at $595 \mathrm{~nm}$ using a spectrophotometer (SpectraMax 190, Molecular Devices, Sunnyvale, CA, USA).

Three independent experiments were performed in triplicate. Thus, a total of 9 discs from each type of cement were used for each bacterium at each time point. The percentage of bacterial growth from each cement disc was calculated according to the following equation: Bacterial growth $(\%)=($ experimental absorbance value $) /($ control absorbance value $) \times 100$.

\section{Ion-releasing abilities}

Plastic molds of $12 \mathrm{~mm}$ internal diameter and $4 \mathrm{~mm}$ height were filled with fresh cement pastes ( $\mathrm{n}=3$ for each material), compacted with a stainless steel spatula, and stored at a relative humidity of $95 \%$ at $37^{\circ} \mathrm{C}$ for $4 \mathrm{~h}$. The samples were then taken out of the molds, individually immersed in $10 \mathrm{~mL}$ of laboratory grade distilled water (Carolina Biological, Burlington, NC, USA) and stored at $37^{\circ} \mathrm{C}$. The exposed surface area of each sample was $264 \mathrm{~mm}^{2}$ (upper and lateral surfaces). The solutions containing the samples were collected at pre-determined endpoint times ( 4 and 24 hours, and 3, 7, 14, and 28 days) and each sample was moved to a new 10 $\mathrm{mL}$ of distilled water at the beginning of each period. Containers with $10 \mathrm{~mL}$ of distilled water and no cement were also used to insure that the detected chemical elements in all solutions were actually leached from the cements and not already present in the water. The solutions collected at 
each time point were utilized for $\mathrm{pH}$ measurement and elemental analyses. The ions analyzed were calcium, fluoride, strontium, sodium, zinc, aluminum, and boron.

The $\mathrm{pH}$ measurements were performed with a $\mathrm{pH}$ Meter and probe (Accumet, Fisher Pittsburgh, PA, USA). The $\mathrm{pH}$ probe was calibrated using standard solutions with $\mathrm{pH}$ values of 4,7 , and 10. The calcium concentration in the solutions was analyzed using flame atomic absorption spectrometry (AAnalyst 200; Perkin-Elmer, Shelton, CT, USA) at $422.7 \mathrm{~nm}$. The tested solutions were diluted with lanthanum chloride solution and calibration was performed using standard calcium solutions $(1.25-5.00 \mu \mathrm{g} \mathrm{Ca} / \mathrm{mL})$. Fluoride determination in the solutions was conducted utilizing a fluoride ion specific electrode (Orion 96-09; Thermo Electron, Beverly, MA,USA) connected to an ion meter (Orion Research Inc., Boston, MA, USA). Standard solutions $(0.01-100.00 \mu \mathrm{g} \mathrm{F} / \mathrm{mL})$ were used for calibration. The standard solutions and test solutions were prepared with $1 \mathrm{~mL}$ of total ionic strength adjustment buffer II (TISAB II, Sigma Aldrich, St. Louis, MO, USA) to $1 \mathrm{~mL}$ of standard/test solution. The readings were expressed in millivolts $(\mathrm{mV})$ and transformed to ppm through linear regression of the calibration curve.

The concentrations of the remaining elements were determined by inductively coupled plasma atomic emission spectrometry (ICP-AES; 6100; Perkin Elmer, Norwalk,CT, USA). The conditions used for the analysis were $27 \mathrm{MHz}$ and $1300 \mathrm{~W}$ of power from a radiofrequency generator, a plasma argon gas flow of $15 \mathrm{~L} / \mathrm{min}$, an auxiliary argon gas flow of $0.8 \mathrm{~L} / \mathrm{min}$, and carrier argon gas flow of $0.2 \mathrm{~L} / \mathrm{min}$. The ICP-AES was calibrated using a four-point calibration method with standard solutions and the detection limits of analyzed elements ranged between 0.004-0.06 ppm. The cumulative releases of all elements were calculated by summing the noncumulative release over time and the obtained values were expressed as ppm. 


\section{Setting time evaluation}

The initial and final setting times of the three cements were tested according to ADA specifications [24] using Gilmore needles (Humboldt MFG., Norridge, IL, USA). The Gilmore needle used to determine initial setting time was $113.4 \mathrm{~g}$ with a $2.12 \mathrm{~mm}$ tip diameter. The Gilmore needle used to evaluate final setting time was $453.6 \mathrm{~g}$ with a $1.06 \mathrm{~mm}$ tip diameter. The setting times were calculated as the time elapsed ( $\mathrm{min}$ ) between the mixing of the powder cement with liquid and the point at which Gilmore needle indentation ceased to be visible on the surface of the materials. A large number of cement samples were initially used to find the approximate initial and final setting times. Molds of $10 \mathrm{~mm}$ in internal diameter and $2 \mathrm{~mm}$ in thickness were filled with fresh cement pastes and stored at $37 \pm 1{ }^{\circ} \mathrm{C}$ and $95 \%$ relative humidity. As the initial or final setting times approached, the samples were tested every minute inside the incubator to determine the exact Gilmore setting time. Gilmore needles were place inside the incubator at least 1 hour before the commencement of testing. The initial and final setting time evaluations were performed in triplicate for each material.

\section{Push-out bond strength test}

The push-out bond strength test was performed as described in a previous study [25]. Intact single rooted human premolars $(\mathrm{n}=30)$ with minimum apical curvature (less than $5^{\circ}$ ) were selected for this study after obtaining local IRB approval. The teeth were stored at $4{ }^{\circ} \mathrm{C}$ in $0.1 \%$ thymol solution and used within 6 months after extraction. All teeth were horizontally decoronated at the level of $0.5 \mathrm{~mm}$ radicular to the facial cementoenamel junction using a water cooled low-speed diamond saw (Buehler Ltd., Lake Bluff, IL, USA) generating $15 \pm 1 \mathrm{~mm}$ long 
Where D1 and D2 were the greater and lesser canal diameters, respectively, $\pi$ was the constant 3.14 and $h$ was the thickness of the obturated root cylinder. 
The amount of force required to displace the obturation material from each root cylinder was measured using a universal testing machine (Sintech Renew 1123, MTS, Eden Prairie, MN, USA). Each root cylinder was fixed on the center of a metal disc that had a central hole with the coronal side facing away from the point of load application. The central hole within the metal disc was slightly larger than the coronal root cylinder diameter to support the root cylinder and allow easy dislodgment of the obturating cement. Cylindrical metal plungers $(9,7$, and $5.5 \mathrm{~mm}$ in diameter for coronal, middle and apical root cylinders, respectively) attached to the loading cell were used to apply compressive force on the obturating cement at a crosshead speed of 0.5 $\mathrm{mm} / \mathrm{min}$. Each metal plunger had a clearance of at least $0.15 \mathrm{~mm}$ from the root wall margins. The maximum dislodgement force of the obturation material was recorded in Newtons and the push-out bond strength $(\mathrm{MPa})$ was calculated for each sample using the following equation: Push-out bond strength $(\mathrm{MPa})=$ the dislodgment force $(\mathrm{N}) /$ adhesion surface area $\left(\mathrm{mm}^{2}\right)$.

After the push out test, the samples were examined with stereomicroscopy (Nikon UM-2, Tokyo, Japan) at $40 \times$ magnification to categorize the failure pattern according to the following classification: (1) adhesive (between dentine and the obturation cement), (2) cohesive (within the obturation cement), or (3) mixed.

\section{Statistical analyses}

All data were checked for normality using the Kolmogorov-Smirnov test and natural logarithm transformations were conducted when necessary to satisfy the normality assumptions. Mixed model ANOVA followed by Fisher protected least significant differences were used to statistically analyze data from antibacterial activity, ion release and push-out bond strength assays. Additionally, one-way ANOVA followed by Fisher protected least significant differences was used to statistically analyze data from both initial and final setting times of different 
cements. Cumulative logit generalized estimating equations (GEE) model including the fixed effects of root location and cement material was used to statistically analyze data from mode of failure after push-out bond strength test. Statistically significant differences were established when $\mathrm{p}<0.05$.

Results

\section{Antibacterial activity against $P$. gingivalis}

Both S-PRG and IRM cements caused a significant reduction in the percentage of bacterial growth compared to the control $(p<0.005)$ at both time points (Table 1$)$. On the other hand, MTA demonstrated a significantly higher percentage of bacterial growth compared to the control after one day of cement preparation $(\mathrm{p}<0.0001)$. S-PRG provided significantly more reduction in bacterial growth compared to IRM and MTA $(\mathrm{p}<0.0001)$ at both time points. Additionally, IRM provided a significantly higher reduction in bacterial growth compared to MTA $(\mathrm{p}<0.0001)$ at both time points.

\section{Antibacterial activity against $E$. faecalis}

All tested cements caused a significant reduction in the percentage of bacterial growth compared to the control at both time points $(\mathrm{p}<0.0001$; Table 1$)$. Furthermore, MTA demonstrated significantly higher reduction in bacterial growth compared to S-PRG and IRM $(\mathrm{p}<0.0001)$ at both time points. Additionally, S-PRG provided significantly higher reduction in bacterial growth compared to IRM $(p<0.0001)$ at both time points. The time factor did not have a significant effect on the percentage of bacterial growth.

\section{Ion releasing abilities}


The non-cumulative and the cumulative releases of all tested ions in the leachates as well as $\mathrm{pH}$ are shown in Table 2. S-PRG cement showed the ability to release 6 different ions throughout the soaking period. S-PRG cement provided an initial burst of boron, zinc and sodium followed by continuous ion release throughout the experiment. Both fluoride and aluminum reached their peak release from S-PRG cement after three days while the release of strontium showed gradual and continuous increase throughout the experiment. MTA cement demonstrated an initial burst of calcium release after 4 hours soaking followed by constant release of calcium at all endpoint times. Sodium, aluminum, and strontium released by S-PRG cement were significantly higher than the same ions released from MTA and IRM at the majority of soaking times $(\mathrm{p}<0.0001)$. S-PRG release of zinc was significantly higher than $\mathrm{Zn}$ released from IRM after 4 hours and 1 day $(\mathrm{p}<0.0001)$ of water soaking.

S-PRG maintained the $\mathrm{pH}$ of the distilled water unchanged throughout the soaking period. IRM also maintained the $\mathrm{pH}$ of the distilled water unchanged until the two week time point but it showed significant acidifying effect compared to the control at the four week time point. Furthermore, S-PRG provided significantly higher $\mathrm{pH}$ of the distilled water compared to IRM at 4 hours $(p<0.0039), 1$ week $(p<0.02)$ and 4 week $(p<0.0002)$ time points. Additionally, the $\mathrm{pH}$ in the presence of MTA cement was significantly higher than that of the control and all other materials at the majority of tested endpoints $(\mathrm{p}<0.03-\mathrm{p}<0.0002)$.

\section{Setting time}

The effect of type of cement was significant for both initial and final setting times $(\mathrm{p}<$ 0.0001). Both initial and final setting times were significantly shorter for IRM and S-PRG 
cements than for MTA $(\mathrm{p}<0.0001)$ (Figures 1A and B). However, no significant difference in initial and final setting times was observed between IRM and S-PRG.

\section{Push-out bond strength}

The location-by-type of cement interaction was significant for push-out bond strength $(\mathrm{p}<0.0001)$. Therefore the pairwise differences of cement materials were performed at each root third (Table 3). MTA had significantly higher bond strength at the coronal and middle parts of the root compared to IRM and S-PRG cements $(\mathrm{p}<0.0001)$. Furthermore, IRM had significantly higher bond strength compared to S-PRG $(\mathrm{p}<0.001)$. The bond strength of IRM at the apical part of the root was significantly higher compared to that of MTA and S-PRG $(\mathrm{p}<0.0001)$. The pushout bond strength of MTA was significantly lower in the apical third of the roots compared to both coronal and middle thirds ( $<<0.0001)$. On the other hand, the push out bond strength of IRM was significant higher in the apical third of the roots compared to coronal third $(\mathrm{p}=0.02)$. Modes of failure were predominately cohesive or mixed except for S-PRG cement on the coronal and middle thirds of the roots, in which adhesive or mixed failure occurred in the majority of the samples. However, the interaction between type of cement used and level of roots was not significant for mode of failure. Furthermore, no significant difference was detected in mode of failure between the three types of cement at all root levels.

\section{Discussion}

The strategy of using various bioactive glass particles in dental applications to improve dentine remineralization has been proposed for decades [26, 27]. However, the incorporation of 
bioactive glass fillers into relatively bioinert materials has gained popularity in recent years as an attempt to achieve more specific biological responses such as inducing antibacterial action [28] or promoting a particular cell response [29]. The antibacterial test used in this study was a modified direct contact test, which is a common antibacterial test used in the endodontic literature to test the antibacterial properties of root cements [4] and sealers [30]. However, the main limitation of the regular direct contact test is that it does not allow evaluation of microorganisms under biofilm conditions [5] because any attempt to disrupt the bacterial biofilm on cement surfaces would lead to crushing of the unset cement samples. Therefore, the modified direct contact test was performed on set cement samples in the current study in order to be able to vortex the tested cement samples and evaluate the bacterial biofilm grown on the specimen surfaces as well as planktonic bacteria around the samples. Future studies aiming to investigate the antibacterial effects of these cements against bacterial biofilms rather than planktonic bacteria are necessary to confirm the antibacterial finding of the current study.

In the present study, S-PRG cement showed significant reduction in $P$. gingivalis growth ranging between $95-99 \%$. The ability of S-PRG cement to nearly eradicate $P$. gingivalis bacteria can be explained by considerable ion release with antibacterial activity such as boron, strontium, and fluoride. The antimicrobial ability of boron-containing compounds has been a subject of interest in recent years [31, 32]. Indeed, boron-based antibacterial therapeutics were suggested to possess strong antibacterial activity against gram-negative infections due to their ability to inhibit various bacterial enzymes $[33,34]$. The current study showed that S-PRG cement was able to release significant amounts of boron throughout all time points. The strong antibacterial effect of S-PRG cement against gram-negative $P$. gingivalis as reported in this study may indicate a potential efficient use of this new root repair material in primary endodontic infections due to the 
presence of higher level of gram-negative bacteria compared to secondary endodontic infections $[35,36]$. However, further studies are required to evaluate the antibacterial properties of S-PRG cement against other gram-negative endodontic pathogens. It is also worth noting that the ability of S-PRG cement to release both fluoride and strontium may also play an additional antibacterial role as the combination of these elements was suggested to have significant antibacterial action [37].

Our study also demonstrated that IRM caused a significant reduction in $P$. gingivalis growth and this reduction was significantly higher for IRM after three days aging. However, the IRM reduction in $P$. ginigvalis growth ranged between $11-23 \%$, which was significantly lower than the bacterial growth reduction caused by S-PRG cement. A previous study also found that a zinc-oxide eugenol based sealer had significant antibacterial effect against $P$. gingivalis [30]. The antimicrobial effect of IRM could be explained by the antibacterial ability of eugenol released from IRM by progressive hydrolysis [38]. No antibacterial effect of MTA against $P$. ginigivalis was observed in the current study, which is consistent with previous studies [30, 39]. All tested cements caused significant but limited reduction on E. faecalis growth ranging from 2-15\% compared to control. Furthermore, MTA provided significantly more reduction of E. faecalis growth compared to IRM and S-PRG cements. The ability of MTA to create an alkaline environment may explain its antibacterial effect against E. faecalis [6]. Previous studies have also demonstrated a significant antibacterial effect of MTA, IRM and glass ionomer like material against $E$. faecalis without being able to totally eliminate the bacterium $[4,5,40]$.

Our study demonstrated that S-PRG released 6 different types of ions throughout all tested time points, which is consistent with previous studies conducted on various S-PRG based materials $[16,41]$. In addition to the expected antibacterial action of some of the ions released 
by S-PRG, ions like fluoride and strontium may play an important role in apatite formation and stability. Previous studies also showed that the combination of fluoride and strontium caused a synergistic remineralization effect $[42,43]$. Ions released from the S-PRG filler were suggested to promote apatite induction [17], increase dentine remineralization [44] and improve dentine acid resistance [45]. Furthermore, S-PRG based root canal sealer was able to establish a superficial surface layer in root canal dentine that is rich with fluoride, strontium, and silicon [45]. This study also confirms the findings of previous studies that showed continuous release of calcium ions from MTA $[2,46]$. On the other hand, no calcium release was detected from S-PRG cement. These findings may indicate distinct differences in the potential mechanism of action of MTA versus S-PRG cement in both antibacterial and remineralization effects. The MTA mode of action is mainly facilitated by the continuous leaching of calcium ions and the increase in local $\mathrm{pH}$ during hydration reaction while the S-PRG mode of action is mainly derived by the release of multiple ions other than calcium and maintaining a relatively neutral $\mathrm{pH}$ of the local environment.

One of the concerns related to the use of S-PRG root cement is the potential cytotoxic effect of some of the ions released, specifically fluoride. However, the cytotoxicity of fluoride is $\mathrm{pH}$ dependent $[47,48]$ and previous studies have shown that fluoride is cytotoxic in acidic $\mathrm{pH}$ but has minimum cytotoxic effect in neutral $\mathrm{pH}[47,48]$. Therefore, the ability of S-PRG cement to maintain the $\mathrm{pH}$ of the soaking water unchanged throughout the soaking period might be helpful in minimizing the cytotoxic effect of fluoride. A recent study suggested that S-PRG filler containing composite was significantly less cytotoxic than ceramic reinforced glass ionomer cement, conventional glass ionomer cement and resin composite [49]. Nevertheless, further 
studies are required to investigate the biocompatibility of S-PRG root repair cements on both cellular and histological levels.

The initial and final setting times of S-PRG reported in this study were 11 and 30 minutes, respectively. This is significantly shorter than MTA initial and final setting times, which were 35 and 200 minutes, respectively. The final setting time of MTA reported in this study is consistent with that reported in the literature, which ranged between 165-250 minutes [2, $50,51]$. The relatively short setting times of S-PRG cement may provide for a reasonable onevisit root repair material, which is not possible with the ProRoot MTA. Cements with traditional acid-base reaction systems such as S-PRG and IRM are expected to set faster than calciumsilicate cements that rely primarily on hydration reactions for setting, which is usually slow [52]. Further studies are required to investigate other variables of S-PRG cement that are related to the setting process such as dimensional stability, solubility and expansion.

Various chemical compositions of root repair materials may lead to different interaction between these materials and radicular dentine. Therefore, push out bond strength was used in the current study to explore the dislocation resistance of various root materials. It is the most reliable mechanical test that can rank the dislodgment resistance of various endodontic materials applied to dentine such as root canal sealers, root repair materials and intraradicular posts [53]. The push-out bond strength was significantly higher for MTA and IRM compared to S-PRG cement at both coronal and middle thirds of the roots. The relatively fast expansion [54] and biomineralization [55] abilities of MTA may improve the mechanical retention of MTA and explain its superior bonding strength on the coronal and middle part of the roots compared to other tested cements. Furthermore, the low push-out bond strength of S-PRG cement might be attributed to the relatively short storage time before evaluation of the bond strength in the current 
study (7 days), which was selected because it is the common storage time used in the vast majority of studies investigating the push-out bond strength of calcium silicate root cements [25, 56]. Fluoride, strontium and silicon ions released from a prototype S-PRG-based root canal sealer were suggested to incorporate into root dentine significantly deeper after one and three months of application compared to one week application [41]. The bond strength of MTA at the apical part of the roots showed a severe and significant drop compared to other locations. Previous studies also showed significantly lower push out bond strength of MTA based sealer [57] and other types of root canal sealers [58] in the apical third of the roots compared to other locations. On the other hand, the present study showed significantly higher bond strength of IRM at the apical part of the roots compared to other locations. No previous studies have compared the bond strength of IRM in different location of the roots. The previously reported significant difference in dentinal tubule density [59,60], orientation [59], and degree of tubular sclerosis [61] between apical and coronal part of the roots may be attributed to the observed significant change in the bond strength at the apical part of the roots.

\section{Conclusion}

The suggested prototype S-PRG root repair cement offered a significantly superior antibacterial effect against $P$. gingivalis bacterium compared to both MTA and IRM and significantly shorter initial and final setting time in comparison to MTA. Furthermore, S-PRG cement showed the ability to continuously release multiple ions up to four weeks including boron, fluoride and strontium. Both MTA and IRM had significantly higher push out bond strength than S-PRG in the coronal and middle third of the roots. Therefore, S-PRG cement may be used as a single-visit root repair material that can release multiple ions with potential 
antibacterial effects against endodontic pathogens. Further studies are warranted to determine the biocompatibility of S-PRG cement.

\section{Compliance with Ethical Standards}

Funding: This study was funded by Shofu Inc. The funding source had no involvement in data collection, analysis, interpretation, or in the decision to submit the article for publication.

Conflict of Interest: The authors declare that they have no conflict of interest.

Ethical approval: All procedures performed in studies involving human teeth were in accordance with the ethical standards of the institutional and/or national research committee and with the 1964 Helsinki declaration and its later amendments or comparable ethical standards.

Informed consent: Informed consent was obtained from all individual participants included in the study.

\section{References}

1. Hirschberg CS, Patel NS, Patel LM et al (2013) Comparison of sealing ability of MTA and EndoSequence Bioceramic Root Repair Material: a bacterial leakage study. Quintessence Int 44:e157-162.

2. Prati C and Gandolfi MG (2015) Calcium silicate bioactive cements: Biological perspectives and clinical applications. Dent Mater 31:351-370.

3. Lee BN, Lee KN, Koh JT et al (2014) Effects of 3 endodontic bioactive cements on osteogenic differentiation in mesenchymal stem cells. J Endod 40:1217-1222.

4. Eldeniz AU, Hadimli $\mathrm{HH}$, Ataoglu $\mathrm{H}$ et al (2006) Antibacterial effect of selected root-end filling materials. J Endod 32:345-349.

5. Lovato KF and Sedgley CM (2011) Antibacterial activity of endosequence root repair material and proroot MTA against clinical isolates of Enterococcus faecalis. J Endod 37:1542-1546.

6. Parirokh M and Torabinejad M (2010) Mineral trioxide aggregate: a comprehensive literature review-Part III: Clinical applications, drawbacks, and mechanism of action. J Endod 36:400-413. 
7. Porter ML, Berto A, Primus CM et al (2010) Physical and chemical properties of new-generation endodontic materials. J Endod 36:524-528.

8. Chong BS, Pitt Ford TR and Hudson MB (2003) A prospective clinical study of Mineral Trioxide Aggregate and IRM when used as root-end filling materials in endodontic surgery. Int Endod J 36:520526.

9. Lindeboom JA, Frenken JW, Kroon FH et al (2005) A comparative prospective randomized clinical study of MTA and IRM as root-end filling materials in single-rooted teeth in endodontic surgery. Oral Surg Oral Med Oral Pathol Oral Radiol Endod 100:495-500.

10. Song M, Shin SJ and Kim E (2011) Outcomes of endodontic micro-resurgery: a prospective clinical study. J Endod 37:316-320.

11. Imazato S, Ma S, Chen JH et al (2014) Therapeutic polymers for dental adhesives: loading resins with bio-active components. Dent Mater 30:97-104.

12. Ikemura K, Tay FR, Endo T et al (2008) A review of chemical-approach and ultramorphological studies on the development of fluoride-releasing dental adhesives comprising new pre-reacted glass ionomer (PRG) fillers. Dent Mater J 27:315-339.

13. lijima M, Ito S, Nakagaki S et al (2014) Effects of immersion in solution of an experimental toothpaste containing S-PRG filler on like-remineralizing ability of etched enamel. Dent Mater J 33:430-436.

14. Suzuki N, Yoneda M, Haruna K et al (2014) Effects of S-PRG eluate on oral biofilm and oral malodor. Arch Oral Biol 59:407-413.

15. Hahnel S, Wastl DS, Schneider-Feyrer S et al (2014) Streptococcus mutans biofilm formation and release of fluoride from experimental resin-based composites depending on surface treatment and S-PRG filler particle fraction. J Adhes Dent 16:313-321.

16. Fujimoto $Y$, Iwasa M, Murayama R et al (2010) Detection of ions released from S-PRG fillers and their modulation effect. Dent Mater J 29:392-397.

17. Ito $S$, lijima M, Hashimoto $M$ et al (2011) Effects of surface pre-reacted glass-ionomer fillers on mineral induction by phosphoprotein. J Dent 39:72-79.

18. Gomes BP, Montagner F, Jacinto RC et al (2007) Polymerase chain reaction of Porphyromonas gingivalis, Treponema denticola, and Tannerella forsythia in primary endodontic infections. J Endod 33:1049-1052.

19. Siqueira JF, Jr., Rocas IN and Silva MG (2008) Prevalence and clonal analysis of Porphyromonas gingivalis in primary endodontic infections. J Endod 34:1332-1336.

20. Rocas IN, Siqueira JF, Jr. and Santos KR (2004) Association of Enterococcus faecalis with different forms of periradicular diseases. J Endod 30:315-320.

21. Siqueira JF, Jr. and Rocas IN (2004) Polymerase chain reaction-based analysis of microorganisms associated with failed endodontic treatment. Oral Surg Oral Med Oral Pathol Oral Radiol Endod 97:8594.

22. Weng Y, Guo X, Gregory R et al (2010) A novel antibacterial dental glass-ionomer cement. Eur J Oral Sci 118:531-534.

23. Xie D, Weng Y, Guo X et al (2011) Preparation and evaluation of a novel glass-ionomer cement with antibacterial functions. Dent Mater 27:487-496.

24. ANSI/ADA Specification \#57 section 5.6 (2008) Laboratory Testing Methods: Endodontic Filling and Sealing Materials.

25. El-Ma'aita AM, Qualtrough AJ and Watts DC (2013) The effect of smear layer on the push-out bond strength of root canal calcium silicate cements. Dent Mater 29:797-803.

26. Oguntebi B, Clark A and Wilson J (1993) Pulp capping with Bioglass and autologous demineralized dentin in miniature swine. J Dent Res 72:484-489.

27. Vollenweider M, Brunner TJ, Knecht $S$ et al (2007) Remineralization of human dentin using ultrafine bioactive glass particles. Acta Biomater 3:936-943. 
28. Hild N, Tawakoli PN, Halter JG et al (2013) pH-dependent antibacterial effects on oral microorganisms through pure PLGA implants and composites with nanosized bioactive glass. Acta Biomater 9:9118-9125.

29. Shalumon KT, Sowmya S, Sathish D et al (2013) Effect of incorporation of nanoscale bioactive glass and hydroxyapatite in $\mathrm{PCL} / \mathrm{chitosan}$ nanofibers for bone and periodontal tissue engineering. Journal of biomedical nanotechnology 9:430-440.

30. Heyder M, Kranz S, Volpel A et al (2013) Antibacterial effect of different root canal sealers on three bacterial species. Dent Mater 29:542-549.

31. Das BC, Thapa P, Karki R et al (2013) Boron chemicals in diagnosis and therapeutics. Future Med Chem 5:653-676.

32. Baker SJ, Ding CZ, Akama T et al (2009) Therapeutic potential of boron-containing compounds. Future Med Chem 1:1275-1288.

33. Minozzi M, Lattanzi G, Benz R et al (2011) Permeation through the cell membrane of a boron-based beta-lactamase inhibitor. PLoS One 6:e23187.

34. Hernandez V, Crepin T, Palencia A et al (2013) Discovery of a novel class of boron-based antibacterials with activity against gram-negative bacteria. Antimicrob Agents Chemother 57:1394-1403. 35. Gomes BP, Endo MS and Martinho FC (2012) Comparison of endotoxin levels found in primary and secondary endodontic infections. J Endod 38:1082-1086.

36. Martinho FC, Leite FR, Nascimento GG et al (2014) Clinical investigation of bacterial species and endotoxin in endodontic infection and evaluation of root canal content activity against macrophages by cytokine production. Clin Oral Investig 18:2095-2102.

37. Guida A, Towler MR, Wall JG et al (2003) Preliminary work on the antibacterial effect of strontium in glass ionomer cements. J Mater Sci Lett 22:1401-1403.

38. Torabinejad M, Hong CU, Pitt Ford TR et al (1995) Antibacterial effects of some root end filling materials. J Endod 21:403-406.

39. Odabas ME, Cinar C, Akca G et al (2011) Short-term antimicrobial properties of mineral trioxide aggregate with incorporated silver-zeolite. Dent Traumatol 27:189-194.

40. Prestegaard H, Portenier I, Orstavik D et al (2014) Antibacterial activity of various root canal sealers and root-end filling materials in dentin blocks infected ex vivo with Enterococcus faecalis. Acta Odontol Scand 72:970-976.

41. Han L and Okiji T (2011) Evaluation of the ions release / incorporation of the prototype S-PRG fillercontaining endodontic sealer. Dent Mater J.

42. Yassen GH, Lippert F, Eckert $G$ et al (2012) The effect of strontium and combinations of strontium and fluoride on the remineralization of artificial caries lesions in vitro. Quintessence Int 43:e95-103. 43. Thuy TT, Nakagaki $\mathrm{H}$, Kato $\mathrm{K}$ et al (2008) Effect of strontium in combination with fluoride on enamel remineralization in vitro. Arch Oral Biol 53:1017-1022.

44. Shiiya T, Tomiyama K, lizuka J et al (2014) Effect of the coating material on root dentin remineralization in vitro. Am J Dent 27:258-262.

45. Ma S, Imazato S, Chen JH et al (2012) Effects of a coating resin containing S-PRG filler to prevent demineralization of root surfaces. Dent Mater J 31:909-915.

46. Gandolfi MG, Taddei P, Siboni F et al (2011) Development of the foremost light-curable calciumsilicate MTA cement as root-end in oral surgery. Chemical-physical properties, bioactivity and biological behavior. Dent Mater 27:e134-157.

47. Hirano S and Ando M (1997) Fluoride mediates apoptosis in osteosarcoma UMR 106 and its cytotoxicity depends on the $\mathrm{pH}$. Arch Toxicol 72:52-58.

48. Leirskar J and Helgeland K (1988) Cytotoxic effects of pH, fluoride and zinc. Int Endod J 21:120-129. 
49. Tamilselvam S, Divyanand MJ and Neelakantan P (2013) Biocompatibility of a conventional glass ionomer, ceramic reinforced glass ionomer, giomer and resin composite to fibroblasts: in vitro study. J Clin Pediatr Dent 37:403-406.

50. Torabinejad M, Hong CU, McDonald F et al (1995) Physical and chemical properties of a new rootend filling material. J Endod 21:349-353.

51. Kaup M, Schafer E and Dammaschke T (2015) An in vitro study of different material properties of Biodentine compared to ProRoot MTA. Head Face Med 11:16.

52. Darvell BW and Wu RC (2011) "MTA"-an Hydraulic Silicate Cement: review update and setting reaction. Dent Mater 27:407-422.

53. Collares FM, Portella FF, Rodrigues SB et al (2015) The influence of methodological variables on the push-out resistance to dislodgement of root filling materials: a meta-regression analysis. Int Endod J 10.1111/iej.12539.

54. lacono F, Gandolfi MG, Huffman B et al (2010) Push-out strength of modified Portland cements and resins. Am J Dent 23:43-46.

55. Reyes-Carmona JF, Felippe MS and Felippe WT (2010) The biomineralization ability of mineral trioxide aggregate and Portland cement on dentin enhances the push-out strength. J Endod 36:286-291. 56. Assmann E, Scarparo RK, Bottcher DE et al (2012) Dentin bond strength of two mineral trioxide aggregate-based and one epoxy resin-based sealers. J Endod 38:219-221.

57. Topcuoglu HS, Demirbuga S, Tuncay O et al (2014) The bond strength of endodontic sealers to root dentine exposed to different gutta-percha solvents. Int Endod J 47:1100-1106.

58. Topcuoglu HS, Tuncay O, Demirbuga $S$ et al (2014) The effect of different final irrigant activation techniques on the bond strength of an epoxy resin-based endodontic sealer: a preliminary study. J Endod 40:862-866.

59. Ferrari M, Mannocci F, Vichi A et al (2000) Bonding to root canal: structural characteristics of the substrate. Am J Dent 13:255-260.

60. Mannocci F, Pilecki P, Bertelli E et al (2004) Density of dentinal tubules affects the tensile strength of root dentin. Dent Mater 20:293-296.

61. Paque F, Luder HU, Sener B et al (2006) Tubular sclerosis rather than the smear layer impedes dye penetration into the dentine of endodontically instrumented root canals. Int Endod J 39:18-25. 
Figure 1A. The means (SE) of initial setting times of the three tested cements. Different letters represent statistically significant differences.

Figure 1B. The means (SE) of final setting times of the three tested cements. Different letters represent statistically significant differences. 
Table 1. The mean percentage (SE) of bacterial growth after exposure to one- and three-day old root cements.

\begin{tabular}{|c|lllll|}
\hline \multirow{2}{*}{ Type of cement } & \multicolumn{2}{|c|}{ E. faecalis } & \multicolumn{2}{c|}{ P. gingivalis } \\
\cline { 2 - 5 } & 1 day & 3 days & 1 day & 3 days \\
\hline S-PRG & $91(5.3) \mathrm{Ca}$ & $90(4.2) \mathrm{Ca}$ & $5(3) \mathrm{Da}$ & $1(0.95) \mathrm{Ca}$ \\
MTA & $85(4.4) \mathrm{Da}$ & $86(2.3) \mathrm{Da}$ & $105(5.5) \mathrm{Aa}$ & $98(6.9) \mathrm{Ab}$ \\
IRM & $98(2.9) \mathrm{Ba}$ & $96(2.1) \mathrm{Ba}$ & $89(4.7) \mathrm{Ca}$ & $77(5.2) \mathrm{Bb}$ \\
Control & $100 \mathrm{Aa}$ & $100 \mathrm{Aa}$ & $100 \mathrm{Ba}$ & $100 \mathrm{Aa}$ \\
\hline
\end{tabular}

Within each bacterium, different uppercase letters indicate a significant difference between different types of cements and the control (set at 100\%) at each time point. Within each bacterium, different lowercase letters indicate a significant difference between one- and threeday old samples of the same cement. 
Table 2. Non-cumulative and cumulative release of ions from tested cements in distilled water.

\begin{tabular}{|c|c|c|c|c|c|c|}
\hline Material & 4 hours & 1 day & 3 days & 1 week & 2 weeks & 4 weeks \\
\hline \multicolumn{7}{|l|}{ Fluoride $(\mathrm{ppm})$ released } \\
\hline S-PRG (non-cumulative) & $16(4) \mathrm{D}$ & $41(2) \mathrm{A}$ & 46(4)A & $41(3) \mathrm{A}$ & $34(2) \mathrm{B}$ & $28(1) \mathrm{C}$ \\
\hline S-PRG (cumulative) & $16(4) \mathrm{F}$ & $57(3) \mathrm{E}$ & $103(6) \mathrm{D}$ & $144(4) \mathrm{C}$ & $178(3) \mathrm{B}$ & $206(3) \mathrm{A}$ \\
\hline MTA & 0 & 0 & 0 & 0 & 0 & 0 \\
\hline IRM & 0 & 0 & 0 & 0 & 0 & 0 \\
\hline \multicolumn{7}{|l|}{ Calcium (ppm) released } \\
\hline S-PRG & 0 & 0 & 0 & 0 & 0 & 0 \\
\hline MTA (non-cumulative) & 43 (9)A & $20(1) \mathrm{B}$ & $21(0.5) \mathrm{B}$ & $21(2) \mathrm{B}$ & $24(2) B$ & $23(2) B$ \\
\hline MTA (cumulative) & $44(9) \mathrm{F}$ & $64(9) \mathrm{E}$ & $85(8) \mathrm{D}$ & $106(11) \mathrm{C}$ & $130(12) \mathrm{B}$ & $153(12) \mathrm{A}$ \\
\hline IRM & 0 & 0 & 0 & 0 & 0 & 0 \\
\hline \multicolumn{7}{|l|}{ Strontium (ppm) released } \\
\hline S-PRG (non-cumulative) & $7(0.4) \mathrm{Ea}$ & $8(1) \mathrm{Ea}$ & $27(3) \mathrm{Da}$ & $60(13) \mathrm{Ca}$ & $84(5) \mathrm{Ba}$ & 97(6)Aa \\
\hline MTA (non-cumulative) & $9(1) \mathrm{Ab}$ & 8 (1)Aa & $3(0.1) \mathrm{Bb}$ & $3(0.2) \mathrm{Bb}$ & $2(0.3) \mathrm{Bb}$ & $2(0.2) \mathrm{Bb}$ \\
\hline IRM (non-cumulative) & $0.2(0.02) \mathrm{Ac}$ & $0.2(0.02) \mathrm{Ab}$ & $0.2(0.03) \mathrm{Ac}$ & $0.2(0.03) \mathrm{Ac}$ & $0.2(0.02) \mathrm{Ac}$ & $0.2(0.006) \mathrm{Ac}$ \\
\hline S-PRG (cumulative) & $7(0.4) \mathrm{Fa}$ & $15(2) \mathrm{Ea}$ & $42(2) \mathrm{Da}$ & $102(13) \mathrm{Ca}$ & $186(17) \mathrm{Ba}$ & $283(23) \mathrm{Aa}$ \\
\hline MTA (cumulative) & $9(1) \mathrm{Fa}$ & $17(0.5) \mathrm{Ea}$ & $20(1) \mathrm{Db}$ & $22(1) \mathrm{Cb}$ & $25(0.3) \mathrm{Bb}$ & $27(0.2) \mathrm{Ab}$ \\
\hline IRM (cumulative) & $0.2(0.02) \mathrm{Fb}$ & $0.4(0.01) \mathrm{Eb}$ & $0.6(0.03) \mathrm{Dc}$ & $0.8(0.04) \mathrm{Cc}$ & $1(0.05) \mathrm{Bc}$ & $1.2(0.05) \mathrm{Ac}$ \\
\hline \multicolumn{7}{|l|}{ Boron (ppm) released } \\
\hline S-PRG (non-cumulative) & $481(50) \mathrm{A}$ & $235(22) \mathrm{B}$ & $168(30) \mathrm{C}$ & $117(18) \mathrm{D}$ & $80(9) \mathrm{E}$ & $51(4) \mathrm{F}$ \\
\hline S-PRG (cumulative) & $481(50) \mathrm{D}$ & $716(43) \mathrm{C}$ & $884(66) \mathrm{B}$ & $1002(56) \mathrm{A}$ & $1082(65) \mathrm{A}$ & $1133(62) \mathrm{A}$ \\
\hline MTA & 0 & 0 & 0 & 0 & 0 & 0 \\
\hline IRM & 0 & 0 & 0 & 0 & 0 & 0 \\
\hline \multicolumn{7}{|l|}{ Aluminum (ppm) released } \\
\hline S-PRG (non-cumulative) & $2.7(0.6) \mathrm{Ea}$ & $12(0.8) \mathrm{Da}$ & $23(4) \mathrm{Aa}$ & $18(2) \mathrm{Ba}$ & $15(0.5) \mathrm{Ca}$ & $12(2.6) \mathrm{Da}$ \\
\hline IRM (non-cumulative) & $0.07(0.01) \mathrm{Ab}$ & $0.07(0.01) \mathrm{Ab}$ & $0.06(0.02) \mathrm{Ab}$ & $0.1(0.005) \mathrm{Ab}$ & $0.09(0.01) \mathrm{Ab}$ & $0.08(0.01) \mathrm{Ab}$ \\
\hline S-PRG (cumulative) & $2.7(0.6) \mathrm{Fa}$ & $14.5(1.1) \mathrm{Ea}$ & $37(2.6) \mathrm{Da}$ & $55.1(0.5) \mathrm{Ca}$ & $70.4(1) \mathrm{Ba}$ & $82(2.9) \mathrm{aA}$ \\
\hline IRM (cumulative) & $0.07(0.01) \mathrm{Fb}$ & $0.14(0.02) \mathrm{Eb}$ & $0.2(0.02) \mathrm{Db}$ & $0.28(0.01) \mathrm{Cb}$ & $0.37(0.004) \mathrm{Bb}$ & $0.5(0.01) \mathrm{Ab}$ \\
\hline MTA & 0 & 0 & 0 & 0 & 0 & 0 \\
\hline \multicolumn{7}{|l|}{ Zinc (ppm) released } \\
\hline S-PRG (non-cumulative) & $26(7) \mathrm{Aa}$ & $15(4) \mathrm{Ba}$ & $5(0.2) \mathrm{Db}$ & $7(2) \mathrm{Ca}$ & $10(0.8) \mathrm{Ba}$ & $12(1) \mathrm{Ba}$ \\
\hline IRM (non-cumulative) & $0.7(0.1) \mathrm{Cb}$ & $5(2) \mathrm{Bb}$ & $11(0.6) \mathrm{Aa}$ & $11(1) \mathrm{Aa}$ & $11(1) \mathrm{Aa}$ & $10(0.4) \mathrm{Aa}$ \\
\hline S-PRG (cumulative) & $26(7) \mathrm{Da}$ & $41(11) \mathrm{Ca}$ & $46(11) \mathrm{Ca}$ & $53(12) \mathrm{Ca}$ & $63(13) \mathrm{Ba}$ & 75 (14)Aa \\
\hline IRM (cumulative) & $0.7(0.1) \mathrm{Fb}$ & $5(2) \mathrm{Eb}$ & $16(2) \mathrm{Db}$ & $27(3) \mathrm{Cb}$ & $38(2) \mathrm{Bb}$ & $48(2) \mathrm{Ab}$ \\
\hline MTA & 0 & 0 & 0 & 0 & 0 & 0 \\
\hline \multicolumn{7}{|l|}{ Sodium (ppm) released } \\
\hline S-PRG (non-cumulative) & 957 (140)Aa & $805(69) \mathrm{Ba}$ & $962(174) \mathrm{Aa}$ & $693(90) \mathrm{Ba}$ & $522(67) \mathrm{Ca}$ & $370(12) \mathrm{Da}$ \\
\hline MTA (non-cumulative) & $77(5) \mathrm{Ab}$ & $90(20) \mathrm{Ab}$ & $62(11) \mathrm{Ab}$ & $41(8) \mathrm{Ab}$ & $36(1) \mathrm{Ab}$ & $44(1) \mathrm{Ab}$ \\
\hline S-PRG (cumulative) & $957(140) \mathrm{Fa}$ & $1762(102) \mathrm{Ea}$ & $2723(256) \mathrm{Da}$ & $3417(188) \mathrm{Ca}$ & $3939(250) \mathrm{Ba}$ & 4309 (262)Aa \\
\hline MTA (cumulative) & $77(5) \mathrm{Fb}$ & $167(16) \mathrm{Eb}$ & $229(27) \mathrm{Db}$ & $270(20) \mathrm{Cb}$ & $306(21) \mathrm{Bb}$ & $350(20) \mathrm{Ab}$ \\
\hline IRM & 0 & 0 & 0 & 0 & 0 & 0 \\
\hline \multicolumn{7}{|l|}{ pH of distilled water } \\
\hline S-PRG & $7.5(0.03) \mathrm{Ab}$ & $7.4(0.09) \mathrm{ABb}$ & $7.4(0.09) \mathrm{ABb}$ & $7.3(0.08) \mathrm{ABb}$ & $7.1(0.03) \mathrm{ABb}$ & $6.9(0.04) \mathrm{Bb}$ \\
\hline MTA & $7.9(0.06) \mathrm{Aa}$ & $7.9(0.04) \mathrm{Aa}$ & $8.1(0.06) \mathrm{Aa}$ & $7.8(0.2) \mathrm{ABa}$ & $7.6(0.04) \mathrm{ABa}$ & $7.5(0.07) \mathrm{BCa}$ \\
\hline IRM & 7.3(0.2)Ac & $7.2(0.09) \mathrm{Ab}$ & $7.1(0.3) \mathrm{ABb}$ & $6.6(0.4) \mathrm{Bc}$ & $6.6(0.5) \mathrm{Bb}$ & $6.2(0.2) \mathrm{Cc}$ \\
\hline Water (negative control) & $7.2(0.3) \mathrm{Abc}$ & $7.2(0.2) \mathrm{Ab}$ & $7.2(0.2) \mathrm{Ab}$ & $7.1(0.2) \mathrm{Ab}$ & $6.9(0.2) \mathrm{Ab}$ & $6.7(0.1) \mathrm{Bb}$ \\
\hline
\end{tabular}


Within each outcome, different lower case letters represent statistically significant differences between different materials and different upper case letters represent statistically significant differences between different time points for the same material. No measurable ions were detected from the negative control (distilled water) except traces of $\mathrm{Na}$ (15-25 ppm). 
Table 3. Mean (SE) of push-out bond strength (MPa) of various tested root canal cements in the apical, coronal and middle part of the roots.

\begin{tabular}{|l|lll|}
\hline \multirow{2}{*}{ Root level } & \multicolumn{3}{|c|}{ Type of root repair cement } \\
\cline { 2 - 4 } & IRM (MPa) & MTA (MPa) & S-PRG (MPa) \\
\hline Apical & $10.06(2.63) \mathrm{Aa}$ & $1.71(0.83) \mathrm{Bb}$ & $2.72(1.55) \mathrm{Ab}$ \\
Middle & $8.25(1.39) \mathrm{Bb}$ & $12.69(3.03) \mathrm{Aa}$ & $4.38(2.60) \mathrm{Ac}$ \\
Coronal & $7.82(2.22) \mathrm{Bb}$ & $12.31(2.68) \mathrm{Aa}$ & $4.50(1.90) \mathrm{Ac}$ \\
\hline
\end{tabular}

Within each cement type, different upper case letters indicate statistically significant differences. Within each location, different lower case letters indicate statistically significant differences. 


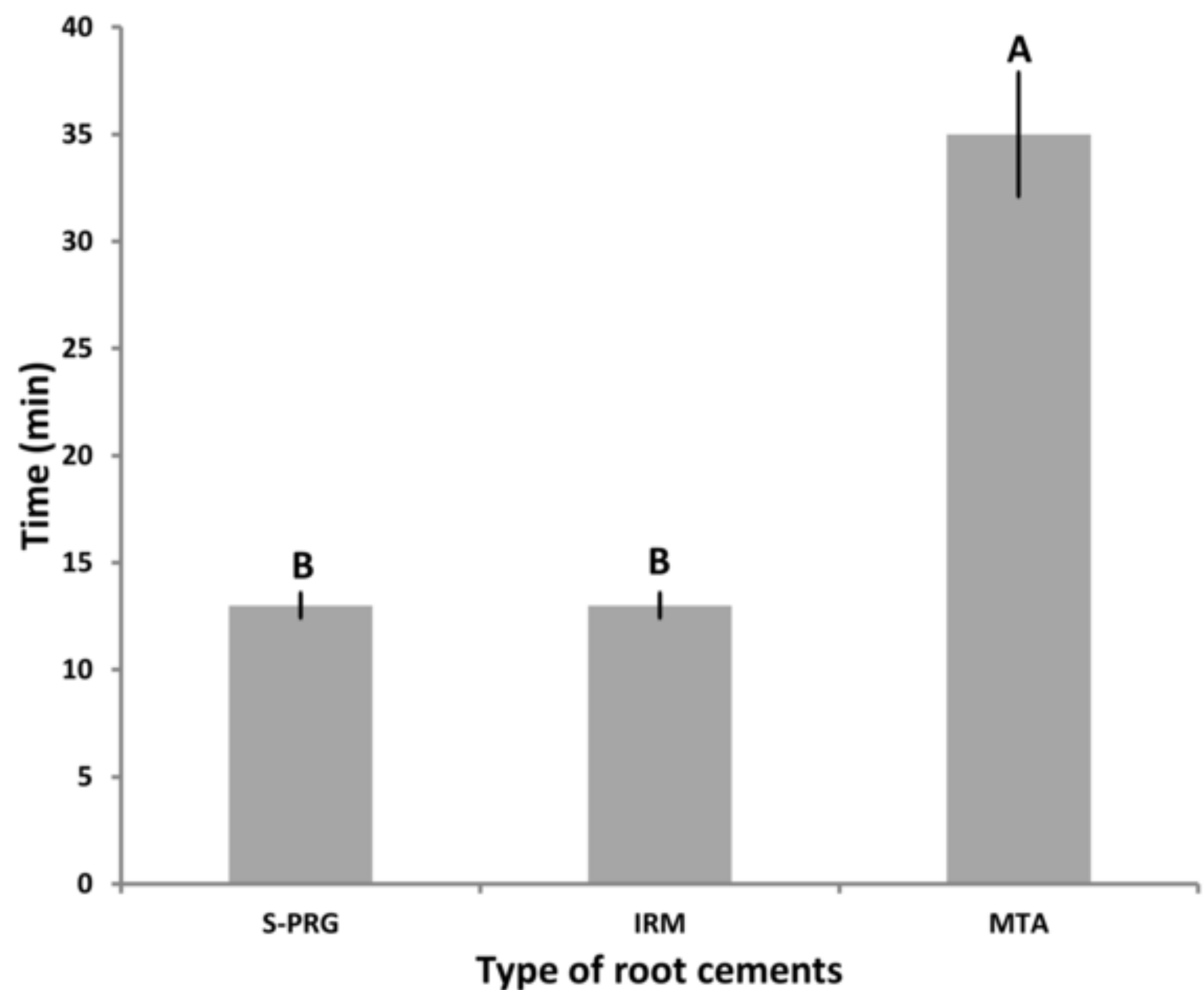




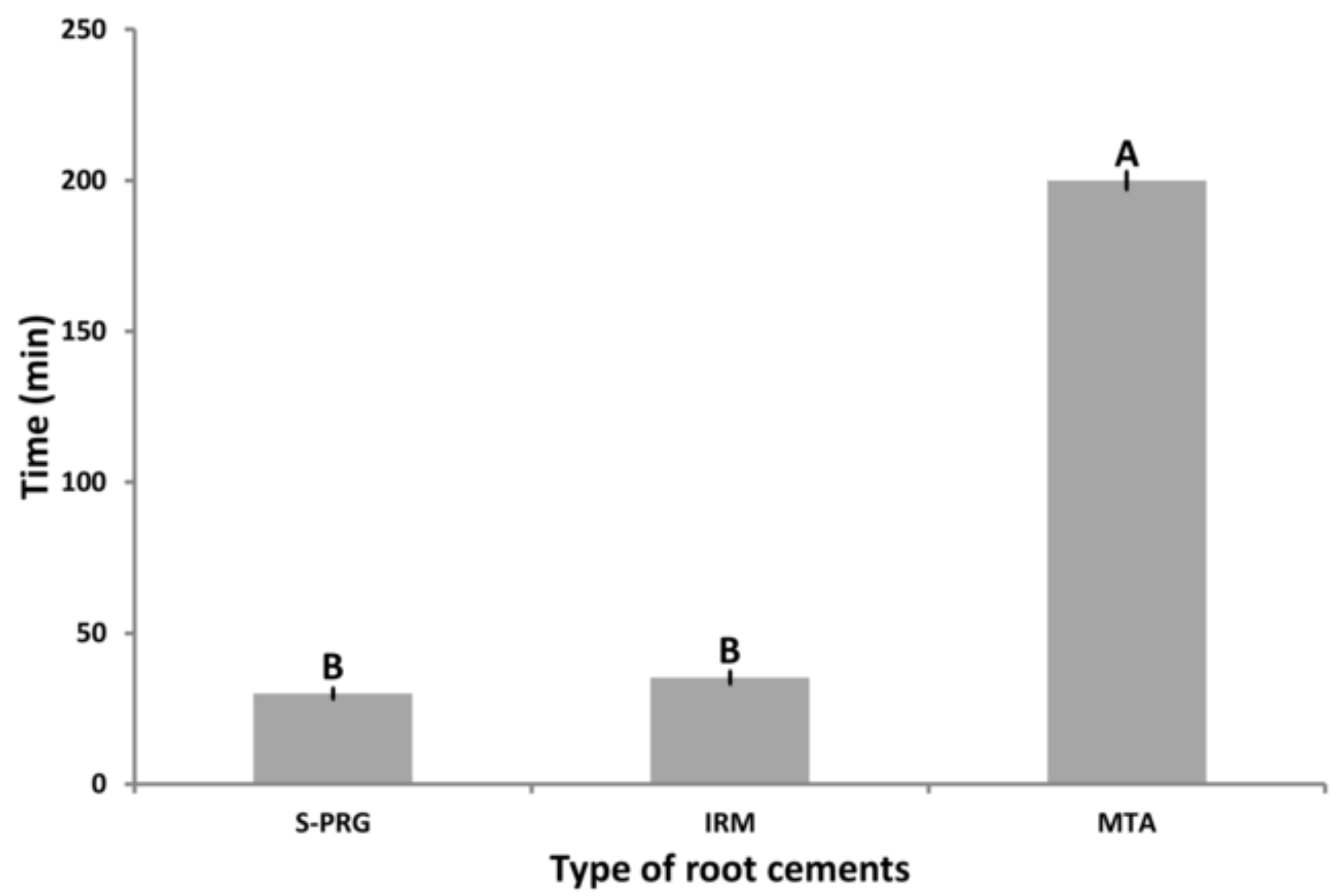

